\title{
CHARACTERISTIC ANALYSIS OF ROTOR DYNAMICS AND EXPERIMENTS OF ACTIVE MAGNETIC BEARING FOR HTR-10GT
}

\author{
Guojun Yang*, Yang Xu, Zhengang Shi, Huidong Gu \\ Institute of Nuclear and New Energy Technology, Tsinghua University \\ Beijing, 100084, China \\ Phone: 86-10-80194001, Fax: 86-10-62771150 \\ E-mail: yanggj@tsinghua.edu.cn
}

\begin{abstract}
A 10MW high-temperature gas-cooled reactor (HTR-10) was constructed by the Institute of Nuclear and New Energy Technology (INET) at Tsinghua University of China. The helium turbine and generator system of 10MW high temperature gas-cooled reactor (HTR-10GT) is the second phase for the HTR-10 project. It is to set up a direct helium cycle to replace the current steam cycle. The active magnetic bearing (AMB) instead of ordinary mechanical bearing was chosen to support the rotor in the HTR-10GT. This rotor is vertically mounted to hold the turbine machine, compressors and the power generator together. The rotor's length is $7 \mathrm{~m}$, its weight is about 1500 $\mathrm{kg}$ and the rotating speed is $15000 \mathrm{r} / \mathrm{min}$. The structure of the rotor is so complicated that dynamic analysis of the rotor becomes difficult. One of the challenging problems is to exceed natural frequencies with enough stability and safety during reactor start up, power change and shutdown. The dynamic analysis of the rotor is the base for the design of control system. It is important for the rotor to exceed critical speeds. Some kinds of softwares and methods, such as MSC.Marc, Ansys, and the Transfer Matrix Method, are compared to fully analyze rotor dynamics characteristic in this paper. The modal analysis has been done for the HTR-10GT rotor. MSC.Marc was finally selected to analyze the vibration mode and the natural frequency of the rotor. The effects of AMB stiffness on the critical speeds of the rotor were studied. The design characteristics of the AMB control system for the HTR-10GT were studied and the related experiment to exceed natural frequencies was introduced. The experimental results demonstrate the system functions and validate the control scheme, which will be used in the HTR-10GT project.
\end{abstract}

Keywords: HTR-10GT, Active Magnetic Bearing, Finite Element Method, Rotor Dynamics, Natural Frequency

\section{INTRODUCTION}

The 10MW high-temperature gas-cooled test reactor (HTR-10) is the first module high-temperature gas-cooled test reactor in the world. It was constructed by INET at Tsinghua University of China. The modular High Temperature gas-cooled Reactor (HTR) combined with direct gas-turbine cycle (closed Brayton cycle) can bring high inherent safety together with high efficiency ${ }^{[1]}$. So the HTRs are considered one of the most potential candidate for the new generation reactors in the 21st century, and several prototype plants are conceptually designed around the world ${ }^{[2-4]}$, such as the PBMR (South Africa), the GT-MHR (Russia, USA, etc.) and the GTHTR300 (Japan) ${ }^{[5]}$.

In the closed Brayton cycle for the HTRs, the gas compressors, turbine and generator are all installed in the primary loop, whose shafts are supported by some kind of special designed bearings. The design of the bearings is a very difficult problem 20 years ago because the helium flow in the reactor primary circuit must keep very clean, and the conventional oil-lubricated bearings may result oil leakage despite adopting complex oil-proof and gas seal means, and the bearing maintenance in the PCU is also very difficult. Fortunately, with the rapid development of the Active Magnetic Bearing (AMB) in the recent years, the contact-free and no-lubricating AMBs are considered as the most competent means to support the turbine shafts in all the designed gas-turbine HTRs, due to their numerous advantages over conventional bearing technology. 
In order to experimentally validate the possibility of creating high performance plants with direct closed gas-turbine cycle and the technology for future commercial applications, the INET of Tsinghua University started the design of the power conversion unit (PCU) with direct gas-turbine cycle for the $10 \mathrm{MW}$ high temperature gas-cooled test modular reactor (HTR-10) at the end of year 2000 in China ${ }^{[6]}$. This so-called HTR-10GT project is supported by the State Science and Technology Committee as a national high technology research and development program. The preliminary design of the PCU system was finished by the mutual efforts of the INET and the OKBM (Russia) at the beginning of year $2003^{[7]}$, just when the HTR-10 reached its full power level. At present, the optimal basic design is being performed by the INET.

This paper focuses on the dynamic characteristics of the HTR-10GT rotor and design of AMB. Because the experiment of full-size AMB system for HTR-10GT is very difficult, the small experiment to exceed natural frequencies will be done. The principle and result of experiment will be introduced in this paper.

\section{BASIC PRINCIPLES OF MAGNETIC BEARINGS}

Magnetic bearings (MB) are a typical mechatronics product. The basic principle of magnetic bearings is to suspend the rotor in a magnetic field by magnetic force, so the rotor can rotate without mechanical contact and wear. Compared with rolling bearings and sliding bearings, magnetic bearings have many advantages, such as being free of contact and contaminating wear, and not requiring lubrication. The rotor can easily reach high speeds. Magnetic bearings have a great future in the aerospace and nuclear industries, and in turbine machinery and vacuum technology.

There are many methods for magnetic bearing classification. There are three kinds of magnetic bearings, classified based on their working principle: active magnetic bearings (AMB), passive magnetic bearings (PMB), and hybrid magnetic bearings (HMB). The rotor is suspended by an electromagnetic force for AMBs. The suspension is accomplished by a permanent magnet force or superconducting force for PMBs. HMBs consist of a combination of the characteristics of AMBs and PMBs. Of these three kinds of bearings, the AMB has been widely applied. The magnetic bearing presented in HTR-10 phase II is an AMB.

Figure 1 illustrates the components and function of a simple bearing. A sensor measures the displacement of the rotor from its reference position, a microprocessor as a controller derives a control signal from the measurement, a power amplifier transforms this control signal into a control current, and the control current generates the magnetic forces within the actuating magnet in such a way that the rotor remains in its hovering position. The control law is responsible for the stability of the hovering state as well as the stiffness and the damping of such a suspension ${ }^{[8]}$.

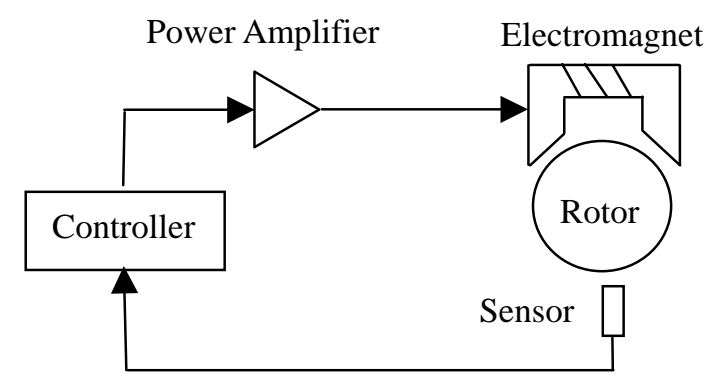

Fig.1 Function principle of the AMB

With the development of related technologies such as rotor dynamics, automation and computer technology, AMB study has made corresponding progress. Theoretic analysis about magnetic bearings has evolved into an integrated system. The study of controller design and flexible rotor dynamics has been developed, and control methods are being improved effectively for controlling complicated rotors. Various algorithms of modern control theories are appearing in corresponding control software. The AMB is progressing towards multifunctional and intelligent application.

MSC.Marc was the first nonlinear commercial finite element software in the world. It has many advantages such as powerful function, friendly interface, the ability to analyze rotors using an abundance of different elements. Many linear and high nonlinear problems for statics and dynamics can be solved by these characteristics of MSC.Marc. 


\section{SYSTEM STRUCTURE AND CHARACTERISTICS}

\subsection{System Outline}

The AMB system is divided into elements inside the PCU and elements outside the PCU. The electromagnets and sensors are located in the PCU, while other AMB control system equipments are located beyond the PCU, including controller facilities and power modules. Its structure along with the turbine rotor in the PCU is shown in Figure 2.

The generator rotor and turbine rotor are connected by a flexible coupling to form a single rotor system in vertical layout, which are suspended by four radial and two axial electromagnetic bearings. Besides, there are catcher bearings to ensure rotor touch down when AMBs fail to work during operation and protect rotor when dynamic loads exceeding AMB load-carrying capacity. The total length of the rotor is about $7 \mathrm{~m}$ and the weight is $1500 \mathrm{~kg}$. The normal rotor operation speed is $15000 \mathrm{rpm}(250 \mathrm{~Hz})$ at the turbine power level of $5.86 \mathrm{MW}$ and efficiency is $86 \%$.

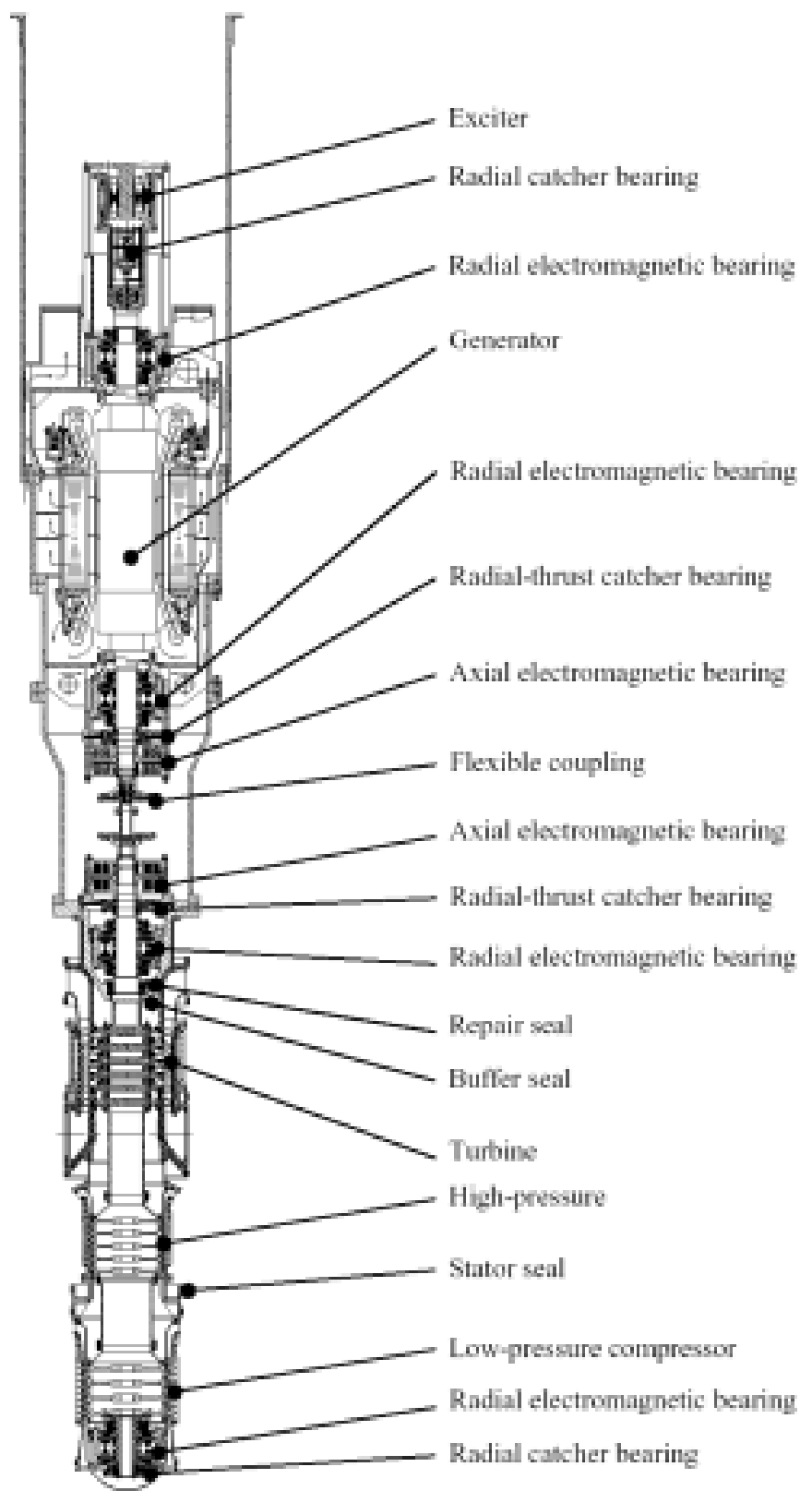

Fig.2. Turbomachine rotor and AMB system layou. 


\section{$\underline{3.2 \text { System Components }}$}

\subsubsection{Active Magnetic Bearing}

The radial and axial magnetic bearings are located in the generator and turbine parts shown in Fig.2. In order to reduce the range of products, magnetic bearings for generator rotor and turbine rotor are designed as the unified size according to the generator rotor load in operation condition. The radial bearing radial gap is $0.15 \mathrm{~mm}$ considering the gap of $0.4 \mathrm{~mm}$ between the compressor stator and blades in order to protect the compressor. The main parameters of the magnetic bearings are listed in Table 1.

\section{Table 1. Main parameters of the active magnetic bearings}

\begin{tabular}{l|c}
\hline \multicolumn{1}{c}{ Parameter } & Value \\
\hline Radial active magnetic bearing & 3000 \\
\hline Lifting capacity, N & $150 / 300$ \\
Interior / outer diameter of stator magnetic circuit, mm & 100 \\
Effective axial length, mm & 7.5 \\
Normal bias current, A & 118 \\
Mass, kg & 0.7 \\
Radial gap between bearing and rotor, mm & 0.15 \\
Radial gap between catcher bearing and rotor, mm & \\
\hline Axial active magnetic bearing & 20000 \\
\hline Lifting capacity, N & $170 / 364$ \\
Interior / outer diameter of stator magnetic circuit, mm & 15 \\
Normal bias current, A & 180 \\
Mass, kg & 1.0 \\
Radial gap between bearing and rotor, mm & 0.3 \\
Radial gap between catcher bearing and rotor, mm & \\
\hline
\end{tabular}

\subsubsection{Position Sensor}

The rotor displacements in radial and axial are monitored by the position sensors, which are of induction type. The sensor consists of sensitive elements located on the stator and an acting element located on the rotor in front of the sensitive elements. The sensitive element is an annular magnetic circuit with 24 poles, of which each 6 poles are grouped to detect the radial displacements in $\mathrm{X}$ and $\mathrm{Y}$ directions. In such design, a kind of 2/3 redundancy working mode for sensor signals can be easily realized. The acting element is an extension made of the laminated ferromagnetic steel, which is fixed on turbine shaft. Windings around the stator perimeter are distributed in order to average and smooth the measure value. This kind of sensor has good sensitivity of no less than $10 \mathrm{mV} / \mu \mathrm{m}$ and resolution of at least $1 \mu \mathrm{m}$. Its cut-off frequency is enough so high $(>5 \mathrm{k} \mathrm{Hz})$ that the phase lag at operation frequency can be neglected. The voltage signal after the sensor modulator can be transferred more than $200 \mathrm{~m}$ without obvious attenuation.

\subsubsection{Controller}

The controllers, as well as all its peripheral equipment, including A/D, D/A, network card, etc., is standard industry type, usually selected as high speed Digital Signal Processing (DSP) computer, which has good stability and excellent hard real-time interrupt processing capability. For example, the new DSP product of TI 6713 has powerful floating-point operation of 1350 MFLOPS and can be adopted as the ideal micro processor of the controller. The A/D converter has 10 channels with $500 \mathrm{kS} / \mathrm{s}$ rate and $16 \mathrm{bit}$ precision, while the D/A converter has 5 channels with $1 \mathrm{MS} / \mathrm{s}$ rate and 14 bit precision. The controller shall have the following functions:

(1) Receive information about displacement, rotation speed and angular position of the turbomachine rotor from the sensor converters;

(2) Receive the control commands from the operation computer to change some parameters of the AMB control system;

(3) Generate and release the current control signals in coil windings according to the specified algorithms and control commands; 
(4) Diagnose the states of the elements of the AMB system and transmit this information to the operator computer via networks;

(5) Release signals about alarm and emergency protection.

\subsubsection{Host Computer}

The operating and monitoring computer (host) lies on the high level control channel, whose type is standard PXI industry computer and its operation system is universal MS Windows. The typical configuration of the host computer can select the NI with $2.3 \mathrm{GHz}$ Pentium $4 \mathrm{CPU}$. The communication between controller and host computer is based on industry network. The main functions of the host computer are listed in the follows:

(1) Establish and change the control algorithms or rules of the AMB;

(2) Start up and stop the AMB control system;

(3) Receive information about the states of AMB components and display this information by different graphical means on the monitor;

(4) Diagnose controller state and make decision;

(5) Log and print information about the state of the AMB control system components;

(6) Send process information to the Instrument and Control (I\&C) system of reactor plant.

\subsubsection{Power amplifier}

The power amplifier receives the control signal in analog voltage from the controller and keeps the current in the magnet winding according to this voltage signal. Generally speaking, power amplifier is a kind of controlled constant-current source to the inductive reactance. As the power of single amplifier unit is about $4.5 \mathrm{kVA}(300 \mathrm{~V}$, $15 \mathrm{~A})$, switch amplifier is the best type considering the losses and efficiency. In order to reduce the drawback of switch amplifier of sharp oscillation impulsion at stable operation state, special method is selected to realize a relative smoothly current, such as three-state voltage level, two H-bridge connecting in series, high switch frequency of $60 \mathrm{k} \mathrm{Hz}$ and so on. The phase lag is less than $3^{\circ}$ at $200 \mathrm{~Hz}$ to achieve good dynamic characteristics.

\subsubsection{Others}

There are some other auxiliary components, such as main power supply, UPS for backup power source, cables and penetrating connector. Due to space limitation, they don't be introduced detailed in this paper.

\section{COMPARISON OF ANALYTIC METHODS FOR ROTOR DYNAMICS}

Many calculating methods have been presented during the development of rotor dynamics. They are relative to previous calculating propositions and implementation. The modern calculating methods are divided into two kinds: the transfer matrix method (TMM) and the finite element method (FEM).

TMM has many useful characteristics. The order of matrixes does not increase with the increased freedom of the system. Using TMM, it is easier to write programs, less EMS memory is necessary, and calculations are performed more quickly. But the finite element model, which takes all kinds of factors into account, is a more precise model. The calculations are more accurate for complicated systems made up of a rotor and its surrounding structure. FEM did not have the instability of numerical value which occurred often in TMM.

Finding a compatible method and software was essential for analyzing the dynamics of the HTR-10GT rotor. The TMM and two FEM softwares (MSC.Marc, Ansys) were selected to compare a test model which had an analytic solution. The results provide an essential theoretical basis for the dynamics of the HTR-10GT rotor.

Figure 3 shows the test model. It is a hinged girder with equal sections. The girder length $l$ is $0.5 \mathrm{~m}$. The diameter is $0.02 \mathrm{~m}$. The density of material is $7,800 \mathrm{~kg} / \mathrm{m}^{3}$. The Young's modulus is $2 * 10^{11} \mathrm{~Pa}$. The Poisson's ratio is 0.3 .

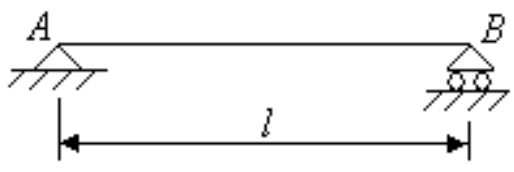

Fig.3 Test model

The TMM, Marc and Ansys were adopted to analyze the modals and natural frequency of the girder. The 
results were compared with the analytical solution. Table 1 shows the first five order natural frequencies of the test model.

Table 2 shows that the MSC.Marc software is more adaptive for analyzing the HTR-10GT rotor. It will be used to analyze the rotor modal of HTR-10GT.

Table 2 The first five order natural frequencies of the test model (Unit: $\mathrm{Hz}$ )

\begin{tabular}{l|l|l|l|l}
\hline & $\begin{array}{l}\text { Analytic } \\
\text { solution }\end{array}$ & Marc & Ansys & TMM \\
\hline $1^{\text {st }}$-order & 159.1 & 159.1 & 158.7 & 159.0 \\
\hline $2^{\text {nd }}$-order & 636.3 & 636.3 & 630.9 & 635.1 \\
\hline $3^{\text {rd }}$-order & 1431.7 & 1431.7 & 1405.7 & 1425.4 \\
\hline $4^{\text {th }}$-order & 2545.3 & 2545.3 & 2465.6 & 2525.4 \\
\hline $5^{\text {th }}$-order & 3977.0 & 3977.0 & 3787.5 & 3928.8 \\
\hline
\end{tabular}

\section{CHARACTERISTIC ANALYSIS OF ROTOR DYNAMICS}

\subsection{Modal Analysis for HTR-10GT}

The HTR-10GT rotor was divided into two parts for increasing natural frequencies, generator rotor and turbine rotor, with a flexible coupling used to connect the two rotors. Figure 4 and 5 show the structure of the two rotors. The natural frequencies of the two rotors were computed by MSC.Marc software. The sustaining stiffness was 5 $\times 10^{6} \mathrm{~N} / \mathrm{m}$. Table 3 shows the corresponding results. Figure 6 shows the rotor mode.

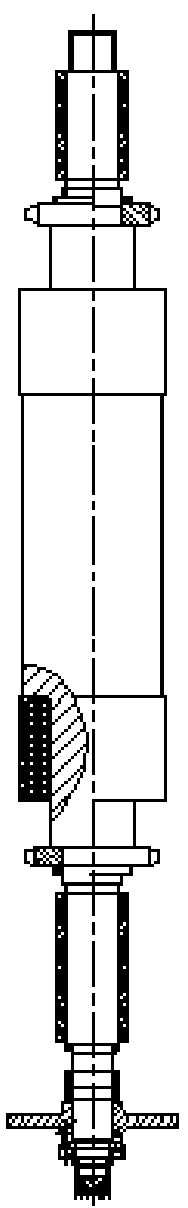

Fig.4 The structure of generator rotor

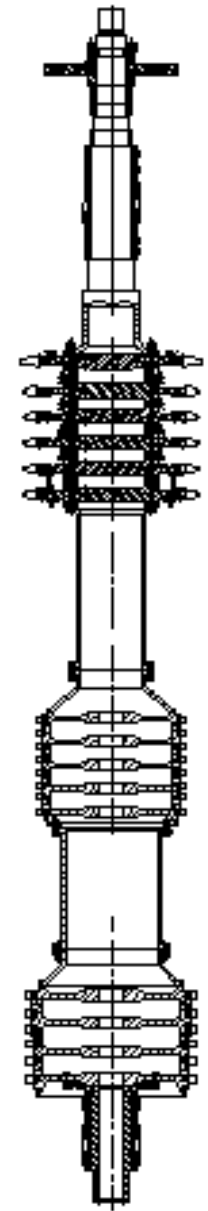

Fig.5 The structure of turbine rotor 
Table 3 Natural frequencies for HTR-10GT rotor (Unit: $\mathrm{Hz}$ )

\begin{tabular}{l|c|c}
\hline & Generator rotor & Turbine rotor \\
\hline Parallel frequency & $13.35\left(f_{\mathrm{g} 1}\right)$ & $14.77\left(f_{\mathrm{t} 1}\right)$ \\
\hline Tilting frequency & $19.31\left(f_{\mathrm{g} 2}\right)$ & $25.96\left(f_{\mathrm{t} 2}\right)$ \\
\hline $1^{\mathrm{st}}$ bending frequency & $58.65\left(f_{\mathrm{g} 3}\right)$ & $61.87\left(f_{\mathrm{t} 3}\right)$ \\
\hline $2^{\text {nd }}$ bending frequency & $129.6\left(f_{\mathrm{g} 4}\right)$ & $141.58\left(f_{\mathrm{t} 4}\right)$ \\
\hline $3^{\text {rd }}$ bending frequency & $327.1\left(f_{\mathrm{g} 5}\right)$ & $345.19\left(f_{\mathrm{t} 5}\right)$ \\
\hline
\end{tabular}
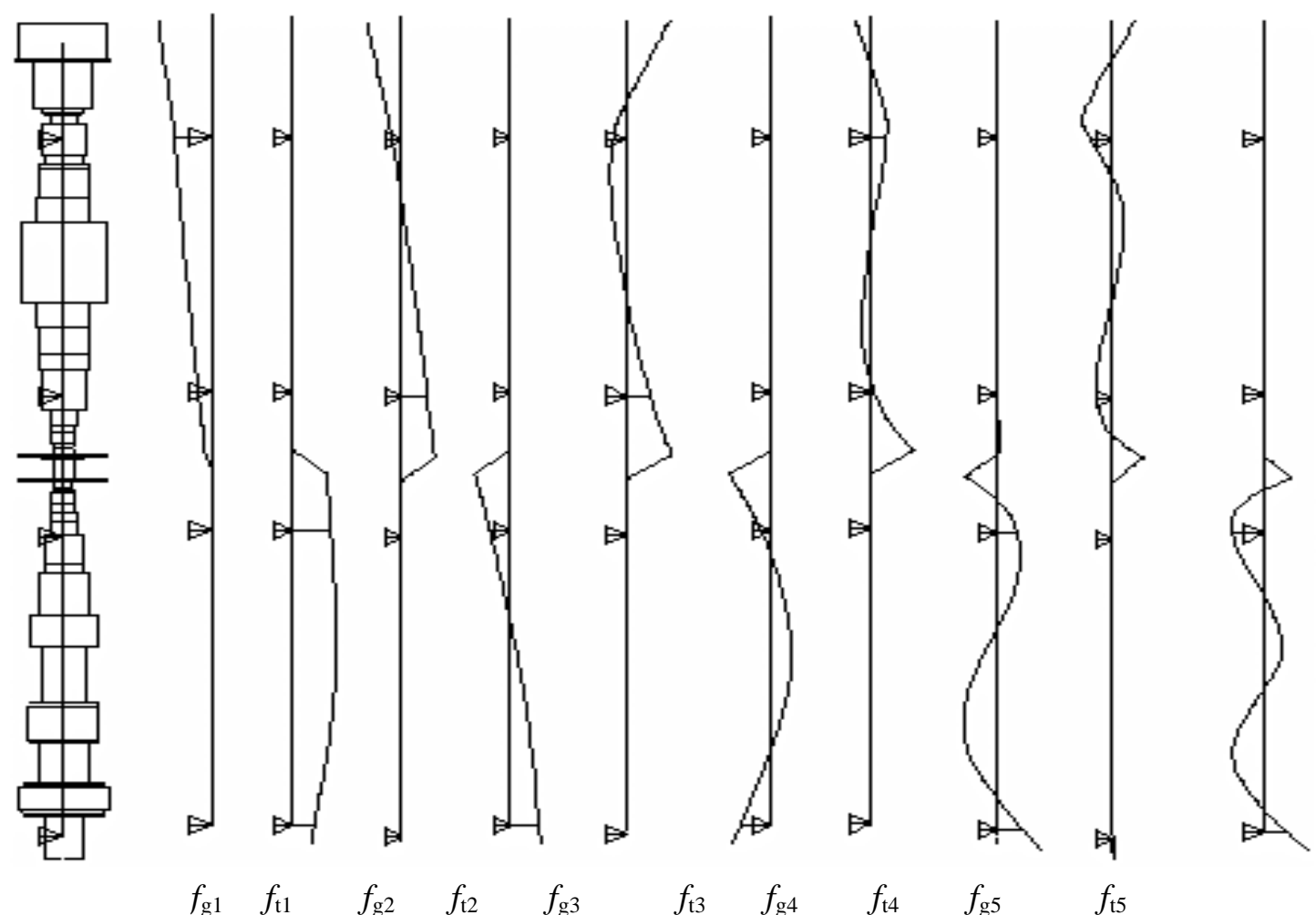

$f_{\mathrm{g} 1} \quad f_{\mathrm{t} 1} \quad f_{\mathrm{g} 2}$

$f_{\mathrm{t} 2} \quad f_{\mathrm{g} 3}$

$f_{\mathrm{t} 3} \quad f_{\mathrm{g} 4}$

$f_{\mathrm{t} 4} \quad f_{\mathrm{g} 5}$

$f_{\mathrm{t} 5}$

Fig.6 Rotor mode for HTR-10GT

The speed of the design was $15,000 \mathrm{r} / \mathrm{min}(250 \mathrm{~Hz})$. Two bending natural frequencies will be exceeded based on Table 3 and Figure 6. It is difficult for the rotor to exceed two bending natural frequencies.

\subsection{The Relationship Between Sustaining Stiffness and Natural Frequency}

The relationship between sustaining stiffness and natural frequency is important to design AMB control system. The relationship was studied to determine the characteristics of rotor dynamics. The range of sustaining stiffness was supposed as $0 \sim 10^{11} \mathrm{~N} / \mathrm{m}$ for the rotors. The relationship between sustaining stiffness and natural frequency was studied by MSC.Marc. Figures 7 and 8 show the relationship curve between the sustaining stiffness and natural frequency. The abscissa is the logarithm coordinate in the two figures.

These results indicate that sustaining stiffness influences natural frequency. If the sustaining stiffness is decreased, its influence on natural frequency is less. With an increase in sustaining stiffness, the change of parallel frequency and tilting frequency becomes higher. However, since these frequencies are rigid, our studies focused on the influence of sustaining stiffness on bending frequency. When the sustaining stiffness was about $10^{9} \mathrm{~N} / \mathrm{m}$, influence on the bending frequency increased. But when the sustaining stiffness was so high that the stiffness was near infinity, the influence of the rotor material characteristics on bending frequency increased. 


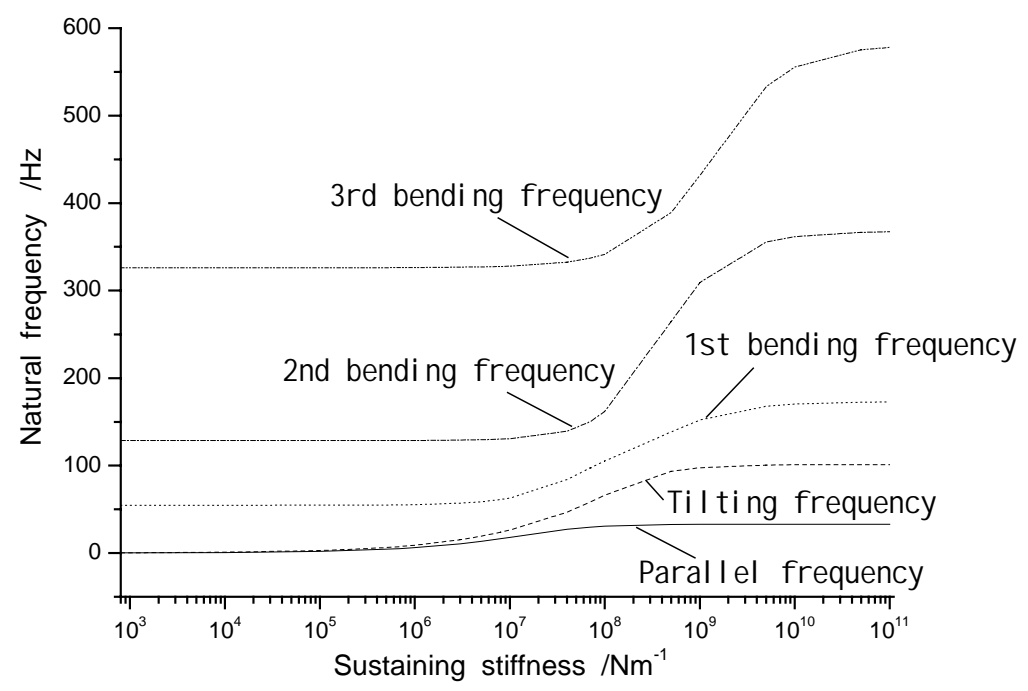

Fig.7 Relationship between sustaining stiffness and natural frequency for generation rotor

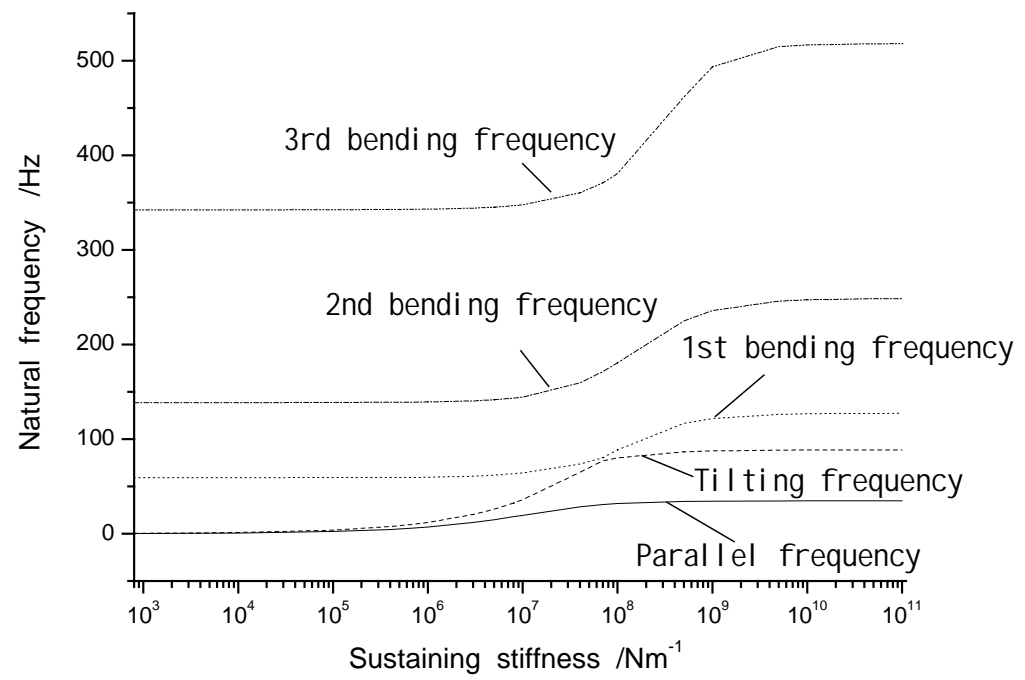

Fig.8 Relationship between sustaining stiffness and natural frequency for turbine rotor

\section{SMALL FLEXIBLE ROTOR TEST RIG}

As we know that there is no application for the AMB used in the PCU of nuclear power plant, especially for supporting a large vertical flexible rotor and passing two bending critical speeds in operation, serials of experiments step by step are necessary for this project, as well as the theoretical analysis.

A small test rig is established to test the control method for flexible rotor and accumulate experience for passing through critical speeds. After the experiment is successful, a test rig with a mode-similar rotor to the actual one will set up to find the way of controlling the actual rotor modes. Finally, the actual turbine rotor system along with the AMB system will be mounted in the PCU vessel of the HTR-10 reactor.

At present, we have already built the test rigs and performed a serial of experiments. On the small flexible rotor test rig, we have succeeded passing through the first bending critical speed (BCS). In the follows, this experimental rig will be described briefly.

\section{$\underline{6.1 \text { System Description }}$}

The emphasis of this experiment is to study the control arithmetic of how to passive the bending critical speed (BCS) and to provide enough experience for the future turbine rotor control. The first BCS is designed as $300 \mathrm{~Hz}$, 
which is higher than that of the actual turbine rotor. It is deliberate to increase some difficult considering the difference between small rotor in experiment and large rotor in the PCU. The structure and main parameters of the setup are shown in Figure 9 and in Table 4 respectively.
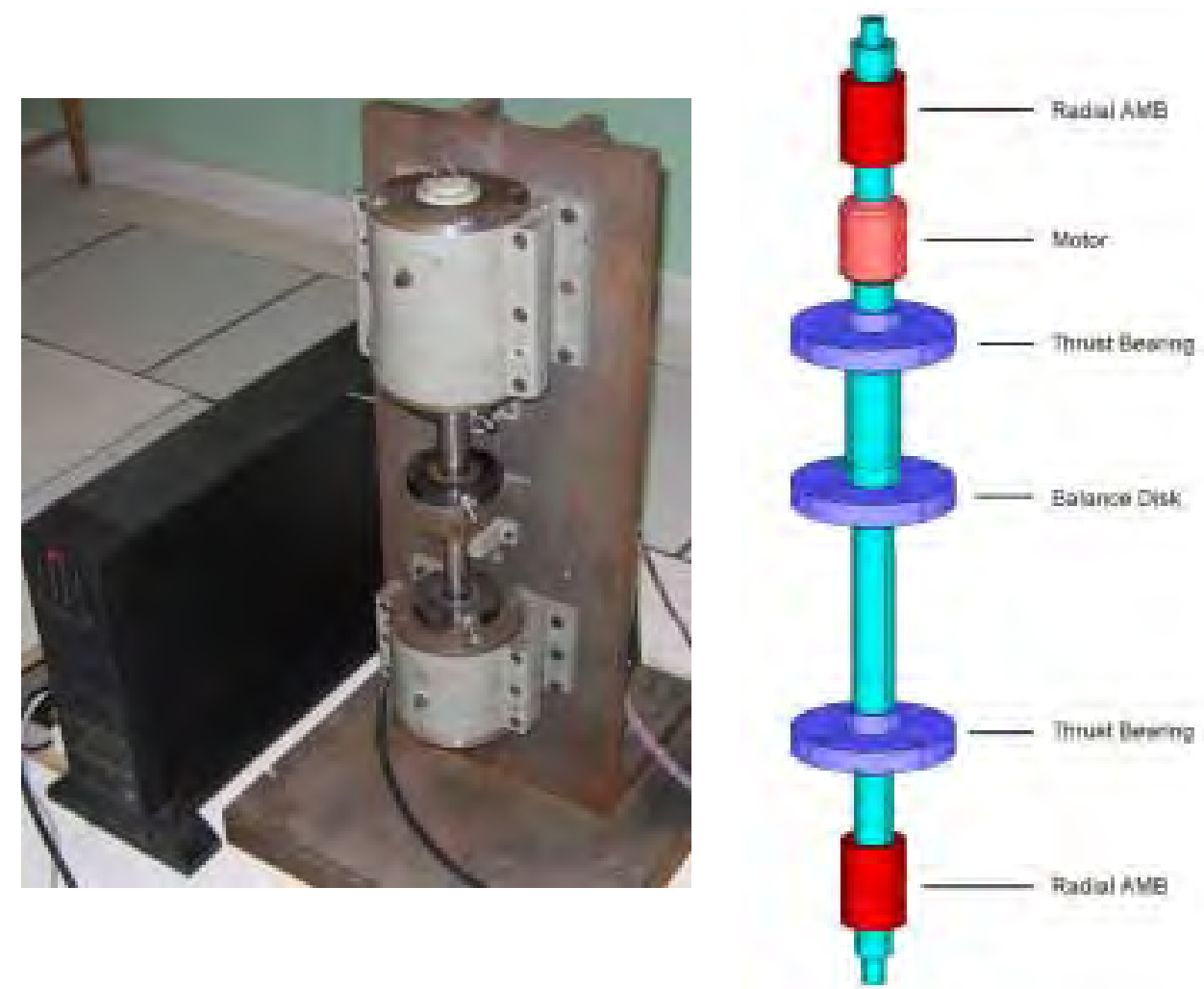

Fig.9 The structure of the small test rig

Table 4 Main parameters of the small setup

\begin{tabular}{l|l}
\hline Rotor Mass & $6.128 \mathrm{~kg}$ \\
\hline Rotor Length & $613 \mathrm{~mm}$ \\
\hline Radial Moment of Inertia & $0.148 \mathrm{~kg} \mathrm{~m}^{2}$ \\
\hline Polar Moment of Inertia & $0.00379 \mathrm{~kg} \mathrm{~m}^{2}$ \\
\hline Air Gap & $0.4 \mathrm{~mm}$ \\
\hline Coils & $300 \mathrm{n}$ \\
\hline Pole Area & $320 \mathrm{~mm}^{2}$ \\
\hline Inductance & $45.2 \mathrm{mH}$ \\
\hline
\end{tabular}

In order to quickly build the test rig, a PC controller is utilized to control the small experiment system on the famous free-charge real-time Linux system, and the sampling ratio is 10k Hz. Although the control system hardware is different from the one that will be used in the actual application, the control model and arithmetic are similar from the view point of mathematical and control.

\section{$\underline{6.2 \text { Modal Analysis }}$}

The finite element method is used to analyze the mode of the rotor. The magnetic bearings are simulated as four constant stiffness spring elements. The stiffness and damping of the magnetic bearing can be adjusted by change the spring element's real constant property. Here in the analysis, the stiffness was set to be $3 \times 10^{4} \mathrm{~N} / \mathrm{m}$, which is obtained from experiment and is much smaller than traditional bearing, and the damping was set to be zero for simplifying the analysis. 
Modal analysis of this rotor is processed. Table 5 gives the analytic data. Figure 10 gives the results of modal analysis.

From the result of modal analysis, modal frequency and modal shape can be well know, which are useful for the sensors distribution design of magnetic bearing. In this result, the gyroscopic effect has not been included yet.

Because of the low bearing stiffness, there are two rigid critical frequencies. These two critical frequencies reflect only the relationship of the rotor's mass and the stiffness. The other two bending frequency are much more concerned about.

\section{Table 5 The rotor system parameters}

\begin{tabular}{rl|rl}
\hline Density: & $\rho=7800 \mathrm{~kg} / \mathrm{m} 3$ & Radius of disc: & $\mathrm{Rd}=50 \mathrm{~mm}$ \\
\hline Young's modulus: & $\mathrm{E}=2.0 \times 10^{11} \mathrm{~N} / \mathrm{m}$ & Radius of axis: & $\mathrm{Rs}=12 \mathrm{~mm}$ \\
& & Radius of lamination: & $\mathrm{Rl}=20 \mathrm{~mm}$ \\
\hline Poisson's coefficient: & $\mu=0.3$ &
\end{tabular}

$28 \mathrm{~Hz}$

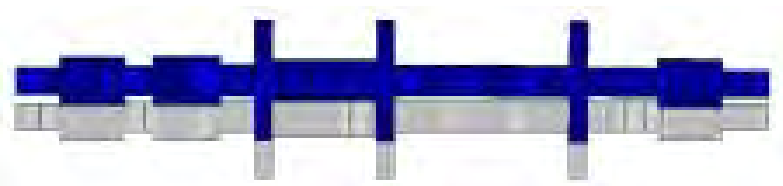

$45 \mathrm{~Hz}$

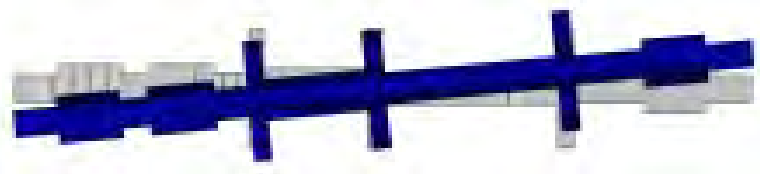

$285 \mathrm{~Hz}$

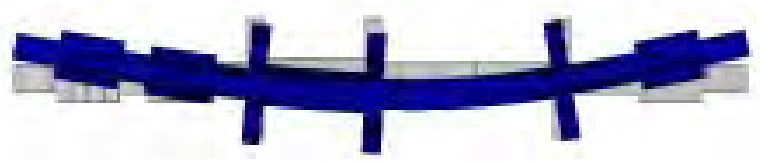

$692 \mathrm{~Hz}$

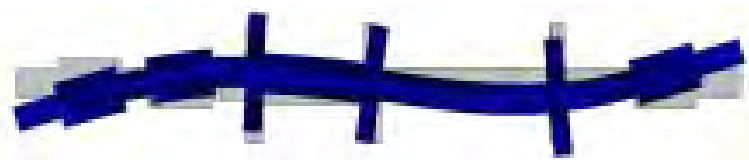

Fig.10 Modal frequency and modal shape

\subsection{Force Response Analysis}

Force response analysis can simulate the force response of the rotor, which can help to identify the main modal frequency. To a complex rotor, the modal analysis can give a serial of eigenfrequency, but only some of them are just the right modal frequency value we need. The harmonic analysis can extract the eigenvector of the modal analysis result, integrate them together, and show the amplitude frequency response characteristics of some special place of the object rotor.

Assume the unbalance force is mostly supply by the middle disk, and the force is $20 \mathrm{~N}$. Figure 11 shows the compare of the top sensor respond of amplitude result and the analysis simulation result.

In this figure, identification result shows the amplitude increase at the front four eigenfrequency. And the harmonic analysis result shows the similar tendency here.

\subsection{Critical Speed Analysis}

The basic differences between the dynamic behavior of a non-rotating body and a rotating one are caused by gyroscopic properties. Typical natural vibrations of a spinning rotor manifest themselves as a "whirling" of the rotor axis, which whirls in the same sense to the rotor spin in a forward whirl or opposite to it in a backward whirl. 
When the gyroscopic effect and the rotor whirling are considered into the modal and harmonic analysis, much more accurate resonant critical frequency result can be obtain, that is very necessary for the controller design. Figure 12 shows the eigenfrequency change as the rotor speed grows.

When taking into account gyroscopic effects, the critical speed result has not been well proved yet. But this result is similar to the result provided by transfer matrix method ${ }^{[9]}$. And this result shows that this testing rotor's critical speed has no much change when the running speed grows up.

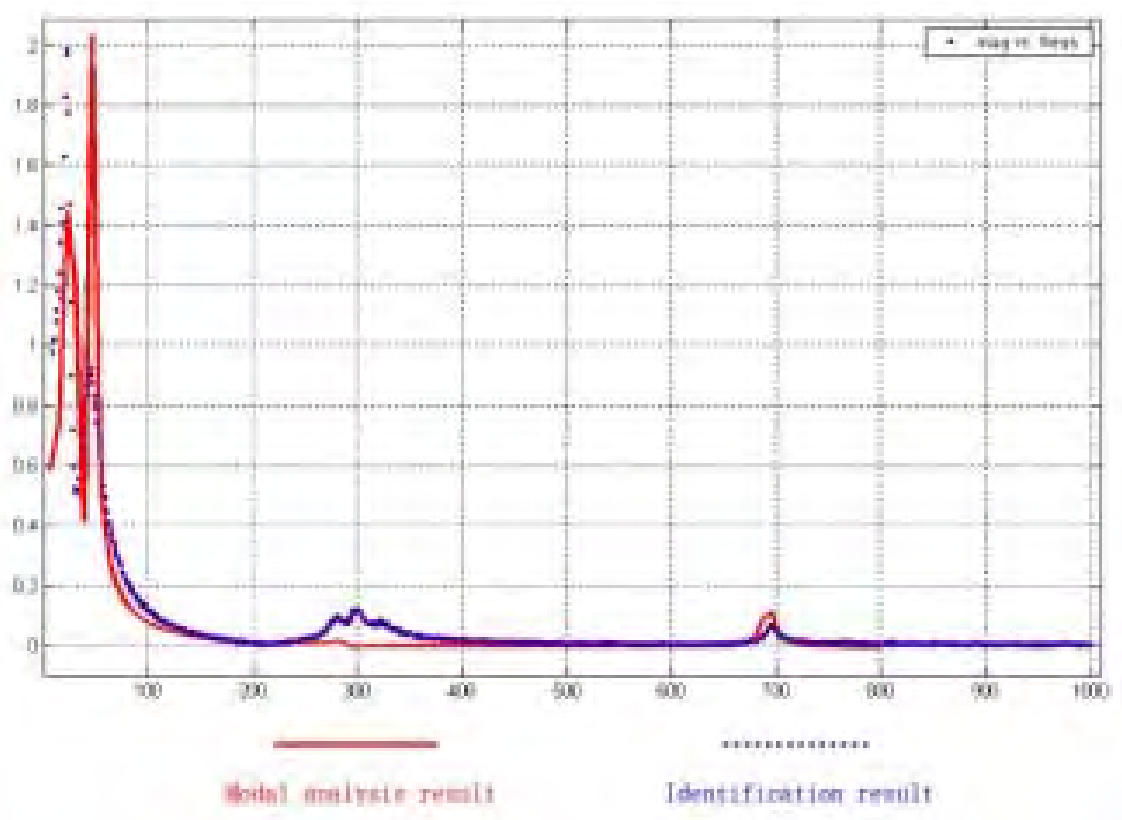

Fig.11 Harmonic analysis of the shaft

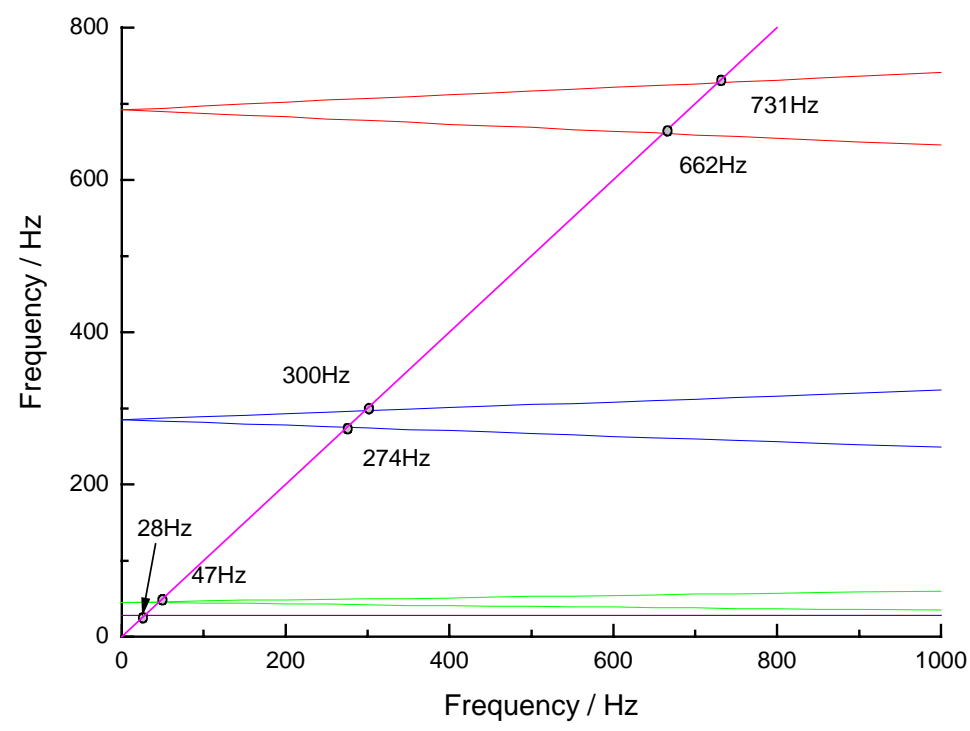

Fig.12 Critical speed analysis with gyroscopic effect

\subsection{Control Design}


Hear a LQG method is introduced to design the controller based on state-space modern control theory. After a process of iteratively changing the weighting factors, a controller with input weighting matrix $\mathrm{R}$ and state weighting matrix $\mathrm{Q}$ is designed.

In the actual rotating experiments, it was found that at some special speeds, the rotor amplitude became too large because of the noise stimulating the nature bending modes of the rotor. In order to restrain the amplitude, some phase compensators are added into the above designed LQG controller at the first two bending frequency.

\subsection{Measuring and Monitoring System}

An online measuring and monitoring system is built for this experiment in order to detect how the AMB system works in operation and make diagnosis whether the system behaves normally or not. Due to the distinct advantages of the VI (Virtual Instruments) technology and LabVIEW (National Instruments) platform, a graphic programming environment on VI as well as standard software on data acquisition and instruments control, are selected as a convenient tool and workbench to build the whole system. The main screen of this system is shown in Figure 13.

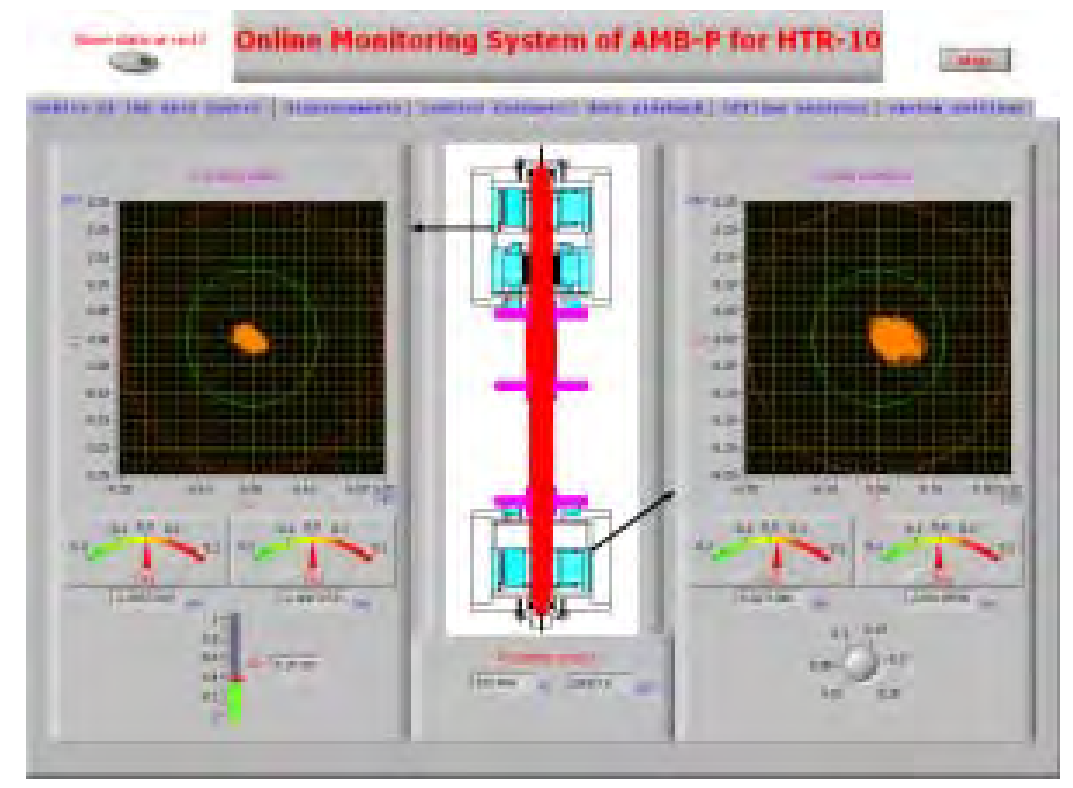

Fig.13 Main screen of the measuring and monitoring rotor system

LabVIEW 7 Express, the latest version, has been chosen as the system software platform. The PCI-6023E data acquisition board, a product also from National Instruments, has been selected as the system data acquisition hardware. According to the requirement and performance of the monitoring system, a personal computer with Windows 2000 system has been chosen to be the foundation and the data processor of the system. Through this system, we can easily and clearly know the operation status including the orbit of the axis centre, the four radial displacement signals and their spectra during its passing the first bending speed.

\subsection{Experiment}

On the small test rig, the passing through BCS experiment was carried out elaborately. The LQG controller along with the phase compensators around the first two bending critical frequencies of $300 \mathrm{~Hz}$ and $700 \mathrm{~Hz}$ has perfect control performance. The rotor passed through the first BCS safely and smoothly and the amplitude was decreased obviously at the first BCS. Even so, the test rig can rotate at the first BCS for a long time without any abnormal phenomenon. Figure 14 shows the top (x1) and bottom (x2) axis loci and their frequency domain properties in passing through the first BCS. 

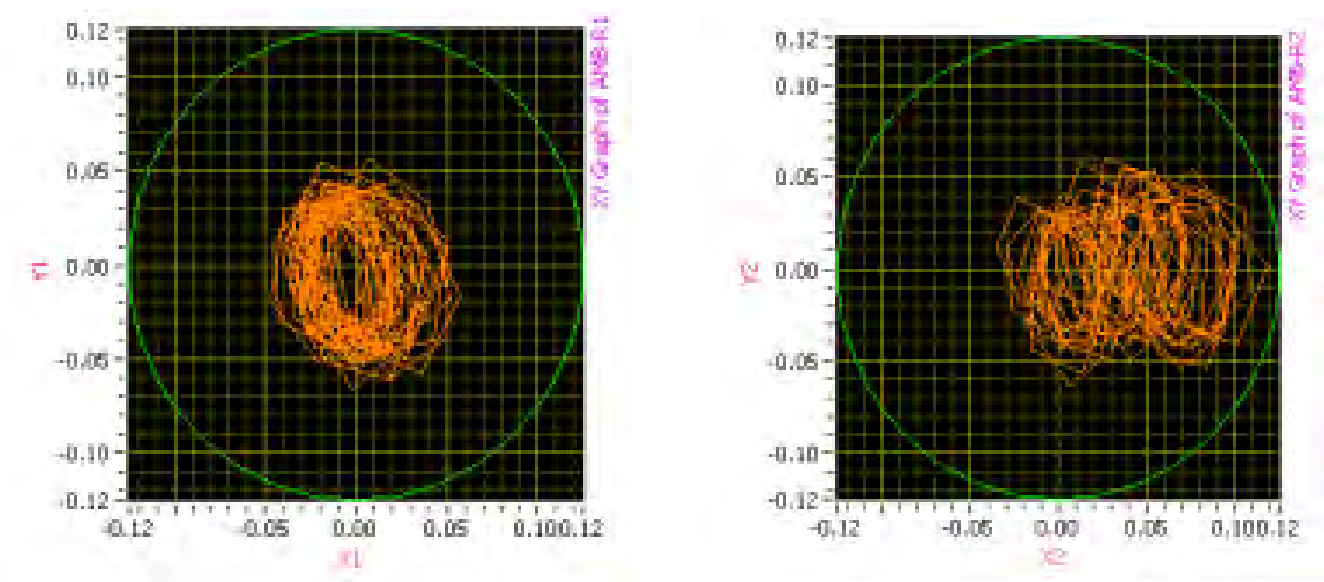

\section{Fig.14 Top (x1) and Bottom (x2) axis loci and frequency properties over the first BCS}

After passing through the first BCS, the amplitude of the axis loci decreases gradually because of the automatically centering effect. This phenomenon agrees well with the rotor dynamic analysis. Now, the rotating speed approaches $500 \mathrm{~Hz}$ and the next step is focus on passing through the second BCS of $700 \mathrm{~Hz}$.

The successful passing through the first BCS verifies that the modeling and control design method is feasible and effective. We also have obtained a lot of experiences in this experiment, which will be certainly useful in the future actual tuning process for the HTR-10GT AMB system.

\section{CONCLUSIONS}

HTR-10GT is the first pebble-bed high temperature gas-cooled test reactor together with direct gas turbine designed and built by the INET in China. The AMB is the key important system to support the turbine rotor in the PCU. The dynamic characteristics and related experiments of the AMB are introduced in this paper. From the experimental results, we have mastered the method and achieved some experience of passing through the bending critical speed. The further design and experiments are being carried out continuously till the whole PCU system installed in the HTR-10 reactor.

\section{ACKNOWLEDGEMENT}

This paper was supported by the 863 High Technology Research and Development Program of China (2001AA511010).

\section{REFERENCES}

[1] Barnert, H., Kugeler, K., 1995. HTR Plus modern turbine technology for higher efficiencies. IAEA-TECDOC-899, Proceedings of a technical committee meeting held in Beijing, China[C], 30 Oct. to 2 Nov, 1995.

[2] Ohashi, K., Okamoto, F., Hayakawa, H., 2000. Modular high temperature reactor (Modular HTR) contributing the global environment protection. Progress in Nuclear Energy, 37, 307-312

[3] Lecomte, M., 2001. Industrial aspects of revisited HTRs. Nucl. Eng. Des. 209, 233-241.

[4] Koster, A., Matzner, H.D., Nicholsi, D.R., 2003. PBMR design for the future. Nucl. Eng. Des. 222, 231-245.

[5] Lei Shi, Lei Zhao, Guojun Yang, etc. Design and Experiments of the Active Magnetic Bearing System for the HTR-10GT. 2nd International Topical Meeting on High Temperature Reactor Technology. Sep. 22-24, 2004. Beijing, China.

[6] Zhang, Z., Yu, S., 2002. Future HTGR developments in China after the criticality of the HTR-10. Nucl. Eng. Des. 218, 249-257 
[7] Shi, L., Yang, G., et al., 2003. Preliminary design of the power conversion unit with direct gas-turbine cycle for the HTR-10. ICONE11, Tokyo, Japan, April 20-23, 2003.

[8] Gerhard Schweitzer, Hannes Bleuler, Alfons Traxler, 1994, Active Magnetic Bearings, Vdf Hochschulverlag AG an der Eth Zürich, 244.

[9] Gu Huidong, A LQG Controller Design for an AMB-Flexible Rotor System, Ninth International Symposium on Magnetic Bearing, Kentucky, USA, 2004.8 